\title{
EXPLORING THE VIRTUAL MARKET OF RECYCLING: A CASE STUDY IMPROVING WASTE REUSE AND RECYCLING IN BANGKOK
}

\author{
Mansoor Ali* \\ Sutima Paaopanchon**
}

\begin{abstract}
Increasing quantities of solid waste is a global challenge for many urban areas in industrializing countries, such as Thailand. United Nations Sustainable Development Goals (SDGs) set clear targets and indicators to improve the waste situation globally. These targets include higher collection rates, safe disposal practices and enhancing the rates of waste reuse and recycling. Bangkok, with a population of 9.5 million (Population of 2018) is facing a number of challenges in solid waste management. These challenges include an increasing quantity of waste, a shortage of waste disposal sites, and reduced incentives to reuse and recycle waste. While at the same time, $80 \%$ of the population has active internet and phone connections (Internet World Statistics, 2018).
\end{abstract}

This paper explores the viability of a virtual waste market in Bangkok by connecting the supply and demand of recyclable waste materials through a mobile application. Particularly, its viability is explored in the nexus between government institutions, informal systems of waste recycling, and in Bangkok population groups. Behaviors and attitudes towards the use of virtual markets to enhance recycling rates have been studied, while key actors (especially those who directly deal with the waste generators) in the recycling chain are also interviewed.

The paper concludes that the concept of a virtual market through a mobile application offers the potential to enhance connection between supply and demand. A virtual market offers the advantage of real time information regarding the material's quality, quantity, prices and locations. It also offers faster and reliable transfer of money. Buyers and sellers can even rate the quality of each other's services. However, to achieve the full advantages and to build a system, all the actors in the chain need to be connected. The study found that itinerant waste buyers and waste pickers directly access the waste and deal with the waste generators. While these groups are the most important links in the chain, they have a low connectivity to mobile phones and hence could not acquire full benefits of the virtual market. Virtual market works well when the connectivity is available to all the relevant groups. The paper concludes that recycling and reuse rates of waste materials can be increased through virtual market if the support is targeted to connect all.

Keyword: Recycling, Waste Reuse, Bangkok, Virtual Market

\section{INTRODUCTION}

Solid Waste Management (SWM) is one of the most crucial and challenging issues for developing countries to solve as highlighted by the United Nations Sustainable Development Goals 11 and 12 (SDGs, 11 and 12). Human activities inevitably generate waste and the method of managing it (i.e. storage, collection, handling and disposal), poses grave risks upon the environment and public health. These risks are further exacerbated by the exponential increase in populations, income levels, industrial activities and unstoppable urbanizations in the twenty first century. Present constantly in the public media, the endangerment of the marine ecosystem caused by lifestyle changes with ever increasing demands and the spiralling increase in plastic packaging to satisfy these demands. Additionally, the lack of adequate planning for environmental measures to tackle these changes, results in ineffectively managed systems.

Issues arise as environmental degradation occurs due to lack of land for the final disposal of municipal solid waste (MSW) and poor management of the waste being generated (Shapkota et.al., 2005). MSW waste stream is naturally more complex as compared to other sector-specific industries due to its heterogeneous nature. Poor SWM consists of odour generated from landfills or open dumpsites, risk of ground and surface water contamination from leachate, as

\footnotetext{
* Mansoor Ali, Visiting Professor, Loughborough University, UK

Email Correspondance: mansoorali57@hotmail.com

** Sutima Paaopanchon, WEDC, Visiting faculty to Loughborough University, UK

Email Correspondance: sutimapaaopanchon@gmail.com
} 
well as public health issues caused by vector-borne diseases, originating from solid waste. To overcome this, a strategic approach known as integrated solid waste management (ISWM) is required to move towards sustainable solid waste management. The ISWM approach addresses the causes of the challenges by prioritising the minimisation of waste generation through recycling, reusing and reducing of waste towards traditional downstream methods of landfilling, incineration and waste-to-energy processes.

Conversely, technological advancement present in modern society offers strong opportunities from a business perspective. Devices such as mobile phones are gaining popularity in both developing and developed countries. Significant investments are made by leading global companies to capture and expand this opportunity. This technological advancement opens a new gateway to potentially improving the SWM systems -offering a low cost two way communicating system leading to other advantages. Bangkok, the capital city of Thailand is located in SouthEast Asia (Figure 1). The capital city has achieved consistent economic development in recent years, shifting from a heavy dependence on the agriculture sector to manufacturing and

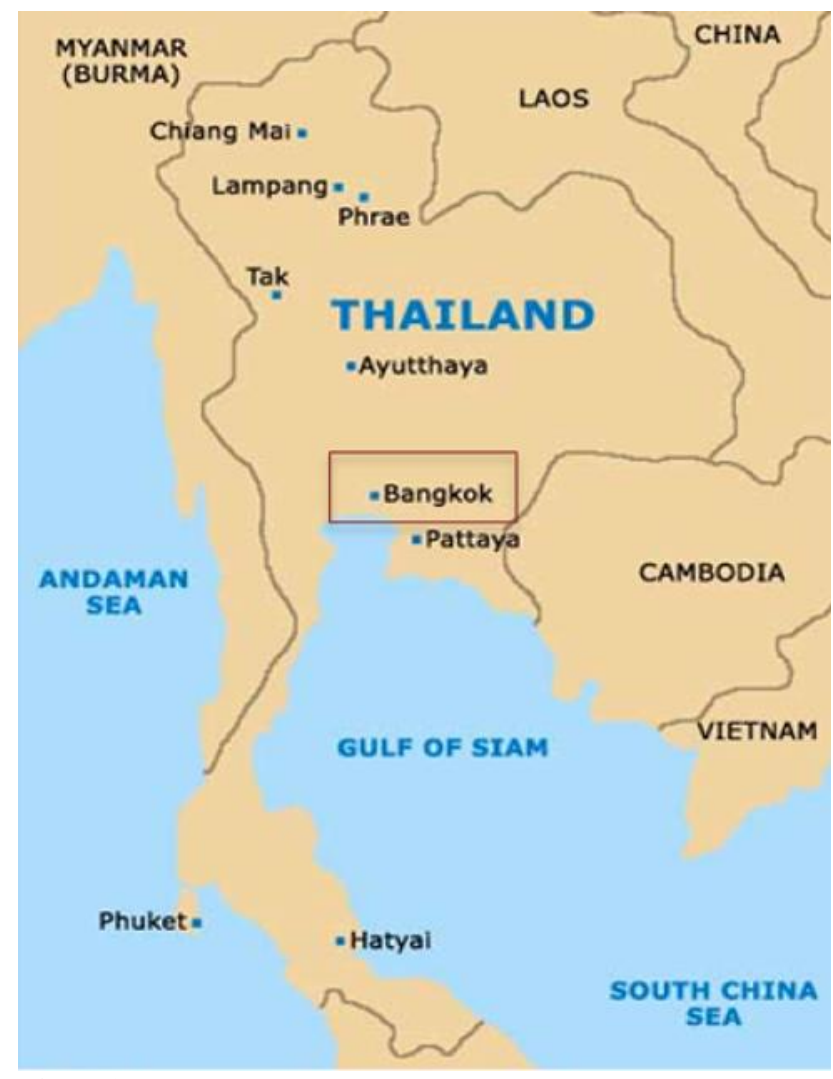

Figure 1: Map of Thailand, illustrating Bangkok Source: www.googleimages.com services, as it becomes an upper middle income country (Chinprateep, 2013). Evidently, the country has experienced rapid export growth, from increases in merchandise exports and tourism resulting in economic growth of 3.9 percent in 2017, the fastest growth rate since 2012 (Nair, et.al., 2018). Based in the city of Bangkok, the aim of this paper is to determine the viability of improving the recycling rate in the city, by creating a virtual market, using mobile applications using mixed methods.

\section{RESEARCH MATERIALS AND METHODS}

To achieve and answer the aim of this research, the researcher sought to:

- Determine the potential issues with low rates of recycling;

- Identify the existing barriers to improve recycling rates;

- Investigate the possibility of overcoming these barriers with the use of virtual markets; and

- Determine the viability of a virtual market.

Hence three research methods consisting of literature and situational review, online questionnaires and semi-structured and unstructured interviews were used to collect data and information.

A literature review illustrated that the topic of SWM and recycling has been thoroughly researched and published in the past, as there lies significant interest to improve the situation. However, available literature has mainly focused on either topic (waste or technology) exclusively instead of the interplay between recycling and mobile applications thus indicating a need for further research. More specifically, the literature that focuses on gathering the public's perspective on using mobile applications to increase recycling rates in Thailand is not there. Literature investigating SWM instead, mainly focuses on market, policies and drivers to encourage society's behaviour and attitude towards waste, recycling and source segregation (Matter, et.al., 2015).

Bangkok has an estimated population of nine million people. The official waste sector is managed by the Bangkok Metropolitan Administration (BMA). The BMA is responsible for and provides the collection service for citizens in Bangkok, which accounts for sixteen percent of the total waste production and with a generation rate of ten thousand tons of municipal solid waste per day. For Bangkok, this is equivalent to approximately 1.14 kilogram per person per day (PCD, 2017). With this high generation rate, challenges in solid waste management arise. This is due to the many 
policies and infrastructure that has not been planned and implemented to ensure sustainable waste management. The key barriers and opportunities that have been identified for improved SWM are technology, economics and social and institutional barriers (Sukholthaman and Shirahada, 2015).

\section{Technological}

Collection and Transport: Provided by the BMA and the Department of Public Cleansing, waste services do not cover the entire urban population because of the growing amount of waste, thus some households are not fully aware of the service provided, resulting in uncollected waste (Sukholthaman and Shirahada, 2015). In addition, formal waste collectors supplement their incomes through scavenging waste, through this the waste collection efficiency reduces. It is reported that crews spend up to forty percent of their time collecting recyclables (Muttamara, Visvanathan and Alwis, 1993). Poor collection service is reflected by the inadequate resources provided by the government (Shapkota et al., 2005).

\section{Economic and Social Barriers:}

Insufficient funds to cover for high capital costs and collection fees: It is difficult to increase tipping/collection fee on public services. To provide effective waste management, twenty to fifty percentage of the municipal budget is used (World Bank, 2018a and 2018b). With fees collected not being sufficient, combined with social opposition, by increasing the collection fees effective solid waste collection service cannot be provided. High percentages of organic refuse in the composition requires regular collection cycle, causing the cost of collection to escalate further.

Public awareness and participation: The public has a negative attitude towards waste sector; therefore, involvement and interaction levels are low. This relates to the education and campaigning programs for separating, reusing, reducing and recycling waste.

\section{Institutional:}

Lack of policies and laws: Generalized and outdated laws and regulations, further complicate the situation. There are taken directly from developed countries without any adaptation. While laws implemented promote the 3R program; yet, fines for litter and open dumping, or charging for plastic bags has not been implemented.

Lack of awareness: Proper waste separation is still not practiced, this links back to the technical factors, and lack of awareness and education.

As mentioned above, the formal waste collectors spend a large portion of their time separating valuable waste. PCD reported that there are high utilization rates $(89.5 \%)$ for the recycled waste collected (PCD , 2017), however this is calculated to only account for $18.5 \%$ of the total waste generated. This is due to the multiple recycling barriers which still prevent the increase in recycling rates. The fundamental reason for low rates of recycling are the uncommon practice of source separation and prohibiting the high rates of recycling as the quality of material is low. Furthermore the following point affect source separation:

- Attitude of households towards environment and climate change.

- Level of awareness of the consequence and economic benefits/ incentive that can be achieved through recycling.

- People's behaviours- as users may act automatically without thinking about the problems associated and revert to their old habits of throwing away waste. This may be the result of busy lifestyles and not giving enough attention to this problem.

- Perceived convenience- some users may think that recycling requires high amount of effort. In addition, the convenience to accessing recycling facilities would also affect the rates.

- Having trust in the waste management infrastructure provided by the responsible agency (in this case the BMA). Policies for recycling schemes must also be clear to ensure high response rate.

- Lack of incentives for recycling-incentives provided by the government to increase the rate of recycling are not yet implemented. Taxes on recycling companies are not put in place to help motivate this positive action.

- Lack of knowledge for proper waste separation- the public is only able to separate easy materials such as glass and plastic bottles, paper and cardboard. Other materials are thrown mixed together creating a lowquality waste.

- Lack of space for storage may also result in less recycling (Ittira Vivongs, 2011), as recyclables are large in volume although they weigh much.

Due to the reasons mentioned above, there is a need to innovate new platforms and tools to increase the rate of recycling. In a market system, there are always two sides to be analysed: demand and supply. This can be applied to the recycling sector also such that households represent the 
supply side where waste (or 'goods') is generated. Manufacturers or companies requiring the 'goods' for recycling represent the demand side.

Primary data for this research was collected using online questionnaires and interviews. The convenience of online questionnaires (versus manually administered ones) allowed large numbers of surveys to be administered quickly, as well as information to be gathered from difficult-to-access groups. The main purpose of this method was to identify the viewpoint of the sampled households in Bangkok, determine the current practices and satisfaction levels, and examine the availability of mobile phones with internet connections, to understand the possibility of introducing mobile applications for improving recycling.

The definition of virtual market in this paper is the market or area in which sellers and buyers can connect using information communication and technology media (ICT). Accessibility to mobile phones has significantly increased from a few privileged users to the mainstream technology. In 2001, the number of mobile phone subscriptions was at six billion, which equates to $86 \%$ global mobile penetration (Mavropoulos et.al, 2015). Moreover, as agreed by World Bank, a publication states "more households in developing countries own a mobile phone than have access to electricity or clean water", which highlights the accessibility of mobile phones to rural areas also (World Bank, 2016). Statistics have shown that the number of internet users have tripled within a decade, from one billion users in 2005 to three and a half billion in 2017 (Statista, 2018). With the mobile phone industry experiencing a dramatic growth the connection between virtual market and business, people and government is stronger. Due to the digital revolution, this has radically altered the way information is disseminated (Hays, Page and Buhalis, 2013).

A related example that adopts this model is Uber. Uber uses the "on-demand" concept of being available anywhere at any time. This concept hence is to be adapted for recycling in the form of application features, including financial transactions and online receipts, as evidence for the users. This is one of the benefits for having a recycling mobile application and creating a virtual market.

Secondly, semi-structured and unstructured interviews were used to gain greater breadth and understanding from stakeholders and experts. Primary data was collected from representatives of different stakeholders involved in the supply chain of the solid waste management and recycling sector in Thailand. These stakeholders comprised of local junk shops, municipalities, itinerant recycle buyers, waste organizations, researchers and an environmental group. The relationship of these stakeholders can be seen in (Figure 2). Global experts in the waste sector were interviewed to validate findings from the questionnaires and stakeholder interviews.

\section{Social Factors}

\section{Perception and attitude of the public}

The interviewees expressed a commonly shared negative perception towards the waste sector. Whether they were in

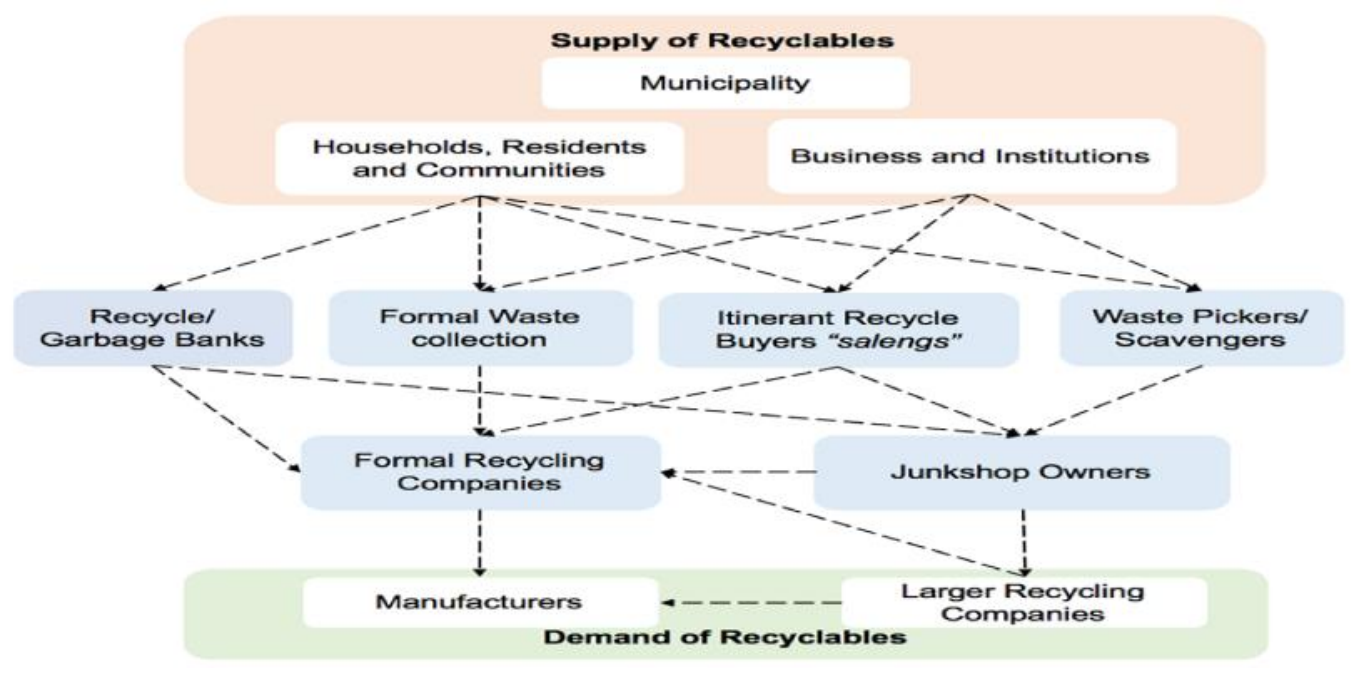

Figure 2: Interaction between stakeholders in waste sector Source: Author adapted from Vassanadumrongdee and KIttipongives, 2018 
Table 1: Summary of the Total Number of Informants

\begin{tabular}{|l|l|c|}
\hline \multicolumn{1}{|c|}{ Informant } & \multicolumn{1}{|c|}{ Data Collection Method } & No. of Informants \\
\hline Group A Household & Questionnaires & 175 \\
\hline Group B Household & Questionnaires & 65 \\
\hline Group C Household & Questionnaires & 87 \\
\hline Stakeholders & Semi-structured and unstructured Interviews & 8 \\
\hline Experts in Field & Semi-structured and unstructured Interviews & 5 \\
\hline
\end{tabular}

Table 1 illustrates a summary of the total number of informants for each method used.

Table 2: Stakeholders and Experts Engaged in the Recycling Industry

\begin{tabular}{|c|c|}
\hline \multicolumn{2}{|l|}{ Stakeholders } \\
\hline Junk shop 1 & Female junk shop owner, taking on the family business. \\
\hline Junk shop 2 & $\begin{array}{l}\text { Male junk shop owner, who was trained to be a construction engineer but decided to start } \\
\text { his own business.Female junk shop owner, taking on the family business. }\end{array}$ \\
\hline Municipality 1 & $\begin{array}{l}\text { Employee in the waste minimization sector at the Pollution Control Department and has } \\
\text { been working in this sector for over twenty five years. }\end{array}$ \\
\hline \multicolumn{2}{|c|}{ Experts in the Waste Field } \\
\hline Expert 1 & Has experience in working in developing countries and focuses on waste strategies. \\
\hline Expert 2 & $\begin{array}{l}\text { Currently working as a consultant in urban development, but has experience in } \\
\text { developing countries. }\end{array}$ \\
\hline Expert 3 & $\begin{array}{l}\text { Currently working in a waste related non-profit organization, focusing solely in } \\
\text { developing countries. }\end{array}$ \\
\hline
\end{tabular}

Following this in the results section, informants are referred either as stakeholders or as experts in the field as shown in Table 2.

\section{Results:}

The feasibility of the innovation investigated was evaluated using six main groups of factors: 1 . Social 2.Health 3.Technological 4.Economic 5. Financial and 6.Institutional 
developing countries the South-East Asia, Sub-Saharan Africa, or in a developed country like the United Kingdom, there was a negative perception to waste and people involved with waste. It seems to be a sector that generally people do not want to get involved in, because it is "not well accepted". According to the junk shop 1 owner, "public thinks it is dirty and that you don't need high education to be in this field" and "the public see people working in the waste sector lower class and with lower education, even family and friends around me said that you (junk shop owner) graduated with an engineering degree why are you going to sell rubbish?". According to the junk shop 2 "it is the job for the lowest of the low". According to Expert 3, "with this negative perception strong in Thailand, trying to change and increase the interaction between the households and the waste sector will remain a challenge."

Nevertheless, perceptions can change with influence from outside. A similar response was made by Municipality 1, where they pointed out that they have been trying to implement change in Bangkok for a long time but have always struggled. As the public did not accept changes or were even aware of the problems associated with waste. It must be noted that addressing a behavioural issue, such as waste, requires time. However, very recently due to the publicity of plastics in the oceans negatively affecting sea animals and killing a whale in Thailand, public awareness of the dangers of plastics has increased. This illustrates that perceptions and awareness can change if the right tools are used. Results from the questionnaire showed that ninety eight percent of the households realized that waste is a problem.

\section{Population Distribution}

The new generation, aged thirty years and below, are the most feasible group for this innovation as they are attached to technology and are familiar with using other service applications in their daily life. Ninety nine percent of the respondents had access to a mobile phone with internet connection, ninety four perscent were familiar with using a mobile application and ninety percent used these applications for basic services, such as transferring money and calling for transport services, which are key features for a recycling application. Therefore, even though the application seems to be useful for households', further investigation revealed that the application seemed more suitable for other stakeholders as well.

\section{Relationship with Salengs (waste pickers) and Households}

While most of the households did not interact directly with salengs through mobile phones, there was a social bond that households had with salengs. Since salengs regularly collect waste in the local areas, they are most likely to meet with the same households every time, thus building a personal connection. Expert 1 stated "I would think that they are used to dealing with the same person, so they will have a personal relationship with the purchaser". However, the introduction of a mobile application risks replacing the human relationship which already exists, thus reducing the viability of this innovation.

\section{Health Factors}

\section{Waste related diseases}

Having a mobile application to provide an on-demand service, helps to solve the issue of a lack of storage space as users can choose when the materials are to be collected, thus directly reducing risks associated with waste-related diseases. However, safety equipment need to be provided to prevent the collectors from being in direct contact with waste. Moreover, protective safety gear creates a professional branding image for the organization, creating trustworthiness, and leading to a larger customer database which could lead to broadening the service and increased recycling rates. Combining this with mobile applications and interaction with existing customers can improve and attract new customers, as negative perspective would decrease.

\section{Technological Factors}

Existing collection method and proposed plans with regards to recyclable materials and collection was commonly done by the informal sector represented by the salengs/ IRB's and junk shops. Expert 2 mentioned that in some cases "the informal sector filled in the gap left by the formal sector". With a strong informal sector already in place, Municipality 1 stated that the recyclable materials recovered were already at a high percentage, thus the market for recovering was already saturated, leading to think that proposing this innovation would not be as useful. Moreover, sixty one percent of the respondents were already satisfied with the current practice, which may be a resistance to change. Some respondents noted that the system should not be interfered with, if it is already working. 


\section{Quality and quantity of waste collected}

A significant factor affecting the quality and quantity of waste collected was source separation. When recyclable materials are contaminated by other materials such as organic waste, the quality declined, directly affecting the price of the materials. There were mixed views regarding source separation in Bangkok. The data collected at household level stated that separation was widely practiced, whilst data collected from the interviews did not corroborate with these results. Junk Shop owners expressed that it was normal for households not to separate the materials properly. Only larger, easier-to-separate materials, such as plastic bottles, cardboard and cans, were separated out of the stream. With households not separating, the viability of the innovation was directly affected, as it would not improve the recycling situation.

\section{Levels of smartphone and mobile application usage}

The main technical factor which affects the feasibility of the innovation is the level of mobile application usage in the area. The saleng interviewed did not own a mobile phone with internet connection or had used mobile applications before, thus suggesting that the innovation is not viable. This may be because, salengs are of a much older age, as the owner of Junk Shop 2 stated, that commonly they are aged between thirty and fifty years, and have never been exposed to the technology. Generally, as people collecting these wastes are often from a lower income group, having to purchase a mobile phone to operate this innovation may not seem attractive to them.

Shifting down the supply chain, other stakeholders with potential were also examined. Owner of Junk Shops 1 and 2 stated that when they are purchasing or selling materials they transfer money through banking applications when sums are higher than ten thousand Baht (equivalent to approximately $£ 220 \mathrm{GBP}$, where $1 \mathrm{GBP}=44$ baht) due to its convenience and digital evidence provided. As these stakeholders already own the device and are familiar with the technology, it seems more viable to implement the application, especially for the supply side, to improve networking and flow of materials.

\section{Economic}

\section{Market demand for recyclable materials}

Materials, including plastic, paper, cardboard, glass and metals, have value in the waste stream and are in demand in the market, but they are already recycled at a high rate. Encouraging the market to increase the recovery of these materials is difficult as the "market is already saturated" according to an official Municipality 1. TIPMSE organization, that works as a link between different stakeholders to improve the waste problem in Thailand, stated that there is high demand for raw materials for the use of manufacturing, and that there is a market demand for the material but it is not being met.

On the other hand, an opposing opinion received from an interview was that from the perspective of working in other developing countries like Africa, Expert 3 stated that some companies believe that working with virgin materials are "easier and cheaper", causing a barrier to recycling.

\section{Mobile money in developing context}

Mobile money has become a new method of transferring capital. For Thailand, this is also widely used, as shown by the results from the household questionnaires, as over ninety percent of the respondents use mobile applications for basic services such as transferring money. However, when junk shops interact with salengs most of the time they pay cash, since each transaction of the waste was relatively less, transactions are often for $£ 11$ (approximately $500 \mathrm{Baht}$ ) or much less, at around £2-3, which makes salengs prefer cash transactions. This observation suggested that salengs would unlikely be in the position to own a mobile phone, with such features as they are living hand-to-mouth and thus prefer cash.

\section{Financial}

\section{Financial status of user}

As the feasibility of using the mobile application to generate a virtual market between households and salengs may not be very high, due to access to restriction to technology, creating interactions between office workers and recycling companies could be more suitable. Since offices generate valuable waste at high quantities and have access to this technology, connecting them directly to junk shops or recycling companies could be an option. Yet, finding alternative jobs, and supporting salengs is required, as cutting them from the loop would result in loss of source of income, and further entrap them in poverty.

\section{Using money as an incentive to increase recycling rates}

The effectiveness of using money as an incentive, depends 
highly on the income level of the user. In this case, as the questionnaire was sent to middle income groups, the dominant response showed selling the materials for environmental instead of monetary purposes. As stated in an existing research, $43.6 \%$ of Bangkok residents recycle for economic incentives, (Vassanadumrongdee and Kittipongvises, 2018). However, when this opinion was compared with other specialists in the field, they felt that money can be the main economic incentive. The experts interviewed felt that when money is involved, the results become more immediate.

An alternative option to mobile money is a rewards program - allowing the use of money to act as an incentive as well as providing flexibility for the reward. Users are thus not bound solely to money or cash, as it may be exchanged for other goods which will help solve the issue where mobile money is still not being commonly used in Thailand currently. Additionally, points can be exchanged for internet credit which helps to overcome the issue of requiring IRBs to purchase internet credit to operate. Nevertheless, such a program would be more practical in low income communities compared to the capital city of Bangkok, since economic drivers are stronger and can be managed properly in those areas.

\section{Institutional}

\section{Legislations/policy/ regulations referring to recycling rates}

When compared to economic incentives, policy incentives are difficult to implement as they take longer to implement and update. The core regulation that municipalities work towards and were mentioned constantly in the interview was the $3 \mathrm{R}$ policy. Municipality 1 viewed that strictly implementing ban on plastic bags like Thailand's neighbouring country, Cambodia, could be too aggressive and thus not be accepted by the society. However, introducing a policy which charges single use plastic bags are more popular methods, however, there are concerns that the government will then receive a backlash.

Coloured PET bottles (Figure 3) are one of the main problems in the waste stream. They do not have a demand in the market, as they cannot be recycled causing an abundance of this material in the landfills. Private companies that have cultivated their brand image using these colours are reluctant to change, due to the fear of losing their consumers. Without legislations put in place to prevent the manufacturing of these products at the source, the problem

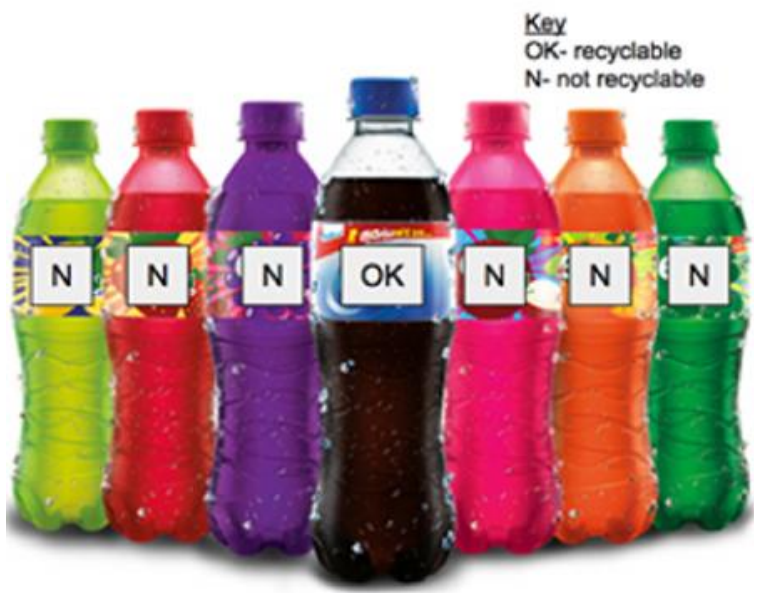

Figure 3: Examples of recyelable PET bottles Source: Author, adapted from Sermsuk, 2018

is unlikely to be solved. Thus, with or without the virtual market, the waste situation would still be an issue. Furthermore, small sachets bags used to package products, such as detergent, also bring complication. Made from multilayered plastics, this product again cannot be recycled, yet is used widely. Specifically, in low income households where purchasing in large quantities are not possible, expert 3 pointed out that the concept of small sachets further exacerbates the poverty traps, when the price is compared per kilogram of product, as small sachets are drastically more expensive. While preventing the purchase of these materials may not be possible, promoting research of new innovations to solve this problem may be beneficial.

\section{Political corruption}

A strong determining factor, which appeared several times during the interviews, was the presence of corruption. This issue was mentioned not only in Bangkok, but also generally in other developing country contexts. As waste is seen to have many economic benefits, politicians involved in this sector tend to neglect solutions proposed which may help the situation.

Municipality 1 voiced their concern about the levels of political corruption which was preventing the improvement of the recycling and waste situation. The interviewee stated that the norm in Bangkok is that the waste collection is subcontracted to a private company. Therefore, when auctioning the contract, a fixed amount is already set aside, hence although the amount of waste generated in Bangkok is reduced, the government still has to pay for the agreed price. This links back to the quality and quantity of waste, as well as the separation of waste, since whether waste is separated 
or not, the set amount of collection has already been agreed to. This illustrates that there are no incentives for the government to promote recycling or other means of reducing waste, as it does not affect their contract with private companies. With a strong link for potential political corruption in this sector, trying to improve the situation will take time and effort to create changes. This also restricts the feasibility of implementing an application.

\section{Conclusion and Recommendations}

\section{Mobile Application as a tool}

Most importantly, the data collected shows that the creation of a virtual market to improve recycling rates is not feasible. The core mechanisms in the supply chain, salengs, do not yet, have access to the technology, due to their economic status, age and habits. In addition, the recycling market for these materials (glass, paper, cardboard, metal, plastic containers) is said to be already saturated. Recycling rates hence, would not increase as these materials already find their way into the market.

\section{Interaction in supply line}

Although the mobile application may not be suitable for salengs, it would be now a useful tool for junk shops to communicate with factories where the technology already exists, hence more opportunity is present here (Figure 4). Developing a specific application may provide ease for factories to communicate. Since there are already other applications specific to communicating and transacting money in use, the developed application must prove itself to be simple and efficient for users to accept and change.

\section{Education about proper waste separation}

Transferring money through the application or mobile money would not be suitable, as salengs come from low income households, making a small living from selling material scraps. Hence, cash is still preferred over mobile money. Instead, considering a reward-based system could be more feasible, as it still provides incentives to promote recycling as well as flexibility. Users should be available to select the reward depending on their preference and needs. Yet this implementation is most suitable in a community context or potentially lower income areas, where monetary drivers are strong.

\section{Reward Base Scheme}

While the public is generally aware that waste is a problem, interviewees stated that they were not knowledgeable on how to separate waste correctly. Existing practices only consists of separating out easy materials, such as paper, cardboard and larger materials such as plastic and glass bottles. This shows that educating the public how to separate waste is essential. Not only will it help to increase recycling rates, but will also allow higher quality material and will result in easier management. Recycling should be taught and emphasized at school level, so that children bring back the knowledge they have learnt from schools to practice at home, creating a knock-on effect. Changing the older generation habits may be more difficult, educating the younger generation will instead lead to a change in the future.

\section{Promotion of recycling campaigns in offices}

On the opposite side of the spectrum, as majority of the people in Bangkok spend a large portion of their time outside the household, most likely in offices, thus the promotion of recycling in offices, organizations or work places can also be a focus. Possible campaigns could include encouraging employees to bring in their waste from home, or separate waste generated within the offices. Since waste is sold based on the weight of the materials, joining together within work places, can result in better prices negotiated,

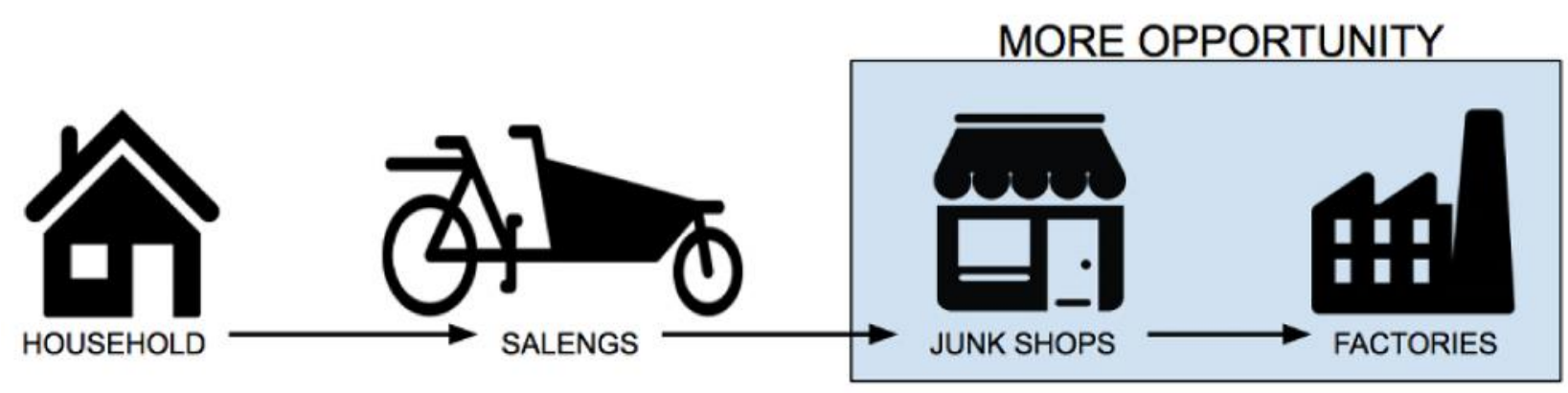

Figure 4: Opportunities in the supply line Source: Author 


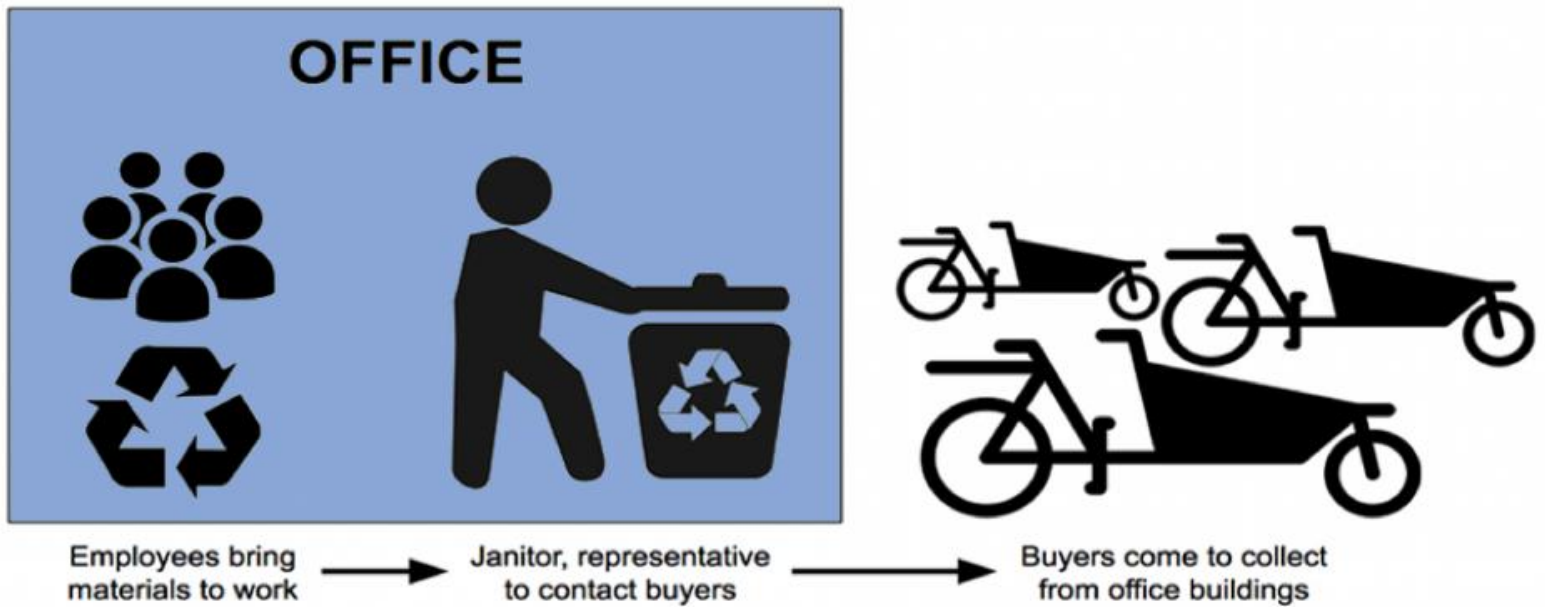

Figure 5: Proposed recycling scheme in offices

as the volume is larger. Offices therefore may wish to build strong connections with buyers in local area to help promote such scheme. This solution would not require the use of applications, but would require the cooperation of different stakeholders. The flow of this process can be seen in (Figure $5)$.

\section{Focus on Reducing and Reusing}

Following the existing $3 \mathrm{R}$ policy of reducing, reusing and recycling, through the analysis of these methods, recycling materials have been said to be "saturated". Since the recycling rates of materials are already high, the focus should be on reducing and reusing. Simple methods of finishing up all the food ordered at cafeterias or minimizing food waste from groceries, can be small lifestyle changes that people can easily adjust to. Regarding these methods, it will require the users to carry additional item with them, whether it is a food container, a reusable water bottle or a cloth bag. Having influencers to promote the cause and highlight the danger of plastic waste may be an aid, but would require cooperation from all stakeholders. Globally, the danger of plastic waste is constantly publicized, hence vocalizing the different approaches to tackle this issue wouldnow.

\section{References:}

Chinpra Teep, A., 2013, “Agricultural Based to Manufacturing Oriented Growth?: In the Case of Thailand", NIDA Case Research Journal, 5 (1): 101.

Hays, S., Page, S.J., and Buhalis, D., 2013, "Current Issues in Tourism Social Media: Its Use by National Tourism Organisations", Current Issues in Tourism. 16 (3): 211-239.

Ittiravivongs, A., 2011, "Factors Influence Household Solid Waste Recycling Behaviour in Thailand: An Integrated Perspective", WIT Transactions on Ecology and The Environment, 167: 437-448.

Matter, A., Ahsan, M., Marbach M., and Zurbrügg, C., 2015, "Impacts of Policy and Market Incentives for Solid Waste Recycling in Dhaka, Bangladesh", Waste Management, 39: 321-328.

Mavropoulos, A., Anthouli, A., and Tsakona, M., 2015, "Recycling, Personal Behaviour, Logistics", Mobile Applications and Waste Management, May: 4-41. 
Muttamara, S., Visvanathan, C., and Alwis, K.U., 1993, "Solid Wastte Recycling and Reuse in Bangkok,” Environmental Systems Reviews, 33: 31-35.

Nair, A., Lathapipat, D., Reungsri, T., Mohib, S., Murciego, G.M., Mishra, D., Shetty, S., Nguyen, H., and Vashakmadze, E., 2018, "Thailand Economic Monitor: Beyong the Innovation Paradox PCD, 2017", Thailand State of Pollution Report 2016.

Sermsuk, 2018, เอส | บริยัท เสริมสุข จำกัด (มหาชน). Image Online, viewed 16 Aug 2018, from http://www.sermsukplc.com/th/ product/detail/est.

Shapkota, P., Coowanitwong, N., Visvanathan, C., and Traenkler, J., 2005, "Potentials of Recycling Municipal Solid Waste in Asia vis-à-vis Recycling in Thailand", Thailand.

Statista, 2018. "Number of internet users worldwide 2005-2017 [online]", Available from: https://www.statista.com/statistics/273018/number-of-internet-users-worldwide/.

Sukholthaman, P. and Shirahada, K., 2015, “Technology in Society Technological Challenges for Effective Development Towards Sustainable Waste Management in Developing Countries: Case Study of Bangkok, Thailand", Technology in Society, 43: 231-239.

Vassanadumrongdee, S. and Kittipongvises, S., 2018, "Factors Influencing Source Separation Intention and Willingness To Pay For Improving Waste Management in Bangkok, Thailand”, Sustainable Environment Research, 28: 90-99.

Walker Smith, J., 2016, "The Uber-All Economy of the Future”, The Independent Review, 20 (3): 383-390.

World Bank, 2016. "Digital Dividends”, Washington DC: International Bank for Reconstruction and Development.

World Bank, 2018a. "Solid Waste Management" Understanding Poverty", viewed 29 Jun 2018, from: http://www.worldbank.org/en/topic/urbandevelopment/brief/solid-waste-management.

World Bank, 2018b, “The World Bank In Thailand: Where we work", [online], viewed 12 Aug 2018, from: http://www.worldbank.org/en/country/thailand/overview. 